\title{
GEOGRAPHICAL INFORMATION SYSTEMS AS A TOOL FOR 3D VISUALIZATION OF LOST ARCHITECTURAL HERITAGE
}

\author{
S. Günay \\ ${ }^{1}$ Oxford Brookes University, Faculty of Technology, Design \& Environment, School of Architecture, Oxford, UK - \\ 17020422@brookes.ac.uk
}

Commission II, WG II/8

KEY WORDS: GIS, BIM, 3D Visualization, Lost Architecture

\begin{abstract}
:
Existing architectural heritage provides information about the architectural and urban characteristics of the civilizations that built them. Their surviving façade compositions, plan organizations, structural and material elements, give clues about various architectural and urban characteristics of these buildings and the periods that they belong to. In the case of lost architectural heritage, it is challenging to know more about these attributes due to the fact that the accessible information about these buildings could be limited. At this point, cartographic and photographic resources provide valuable information about lost architectural heritage. In addition to their geographic locations, information about their dimensions, structural systems, material finishes, colours could be some of the information that can be collected through cartographic and photographic historic documents.

This paper presents a summary of the methodological approach of using Geographical Information System (GIS) for 3D visualization of lost architectural heritage in the case of Izmir - Turkey, by using 1905 fire insurance plans of Charles E. Goad.
\end{abstract}

\section{INTRODUCTION}

\subsection{Lost Architectural Heritage}

Management of historic data is critical for urban and architectural conservation decision making process. Digital technologies allow suitable environment for data management and visualization of these complex data in various forms. It is even more important to manage and utilize complex historic documents if the subject of architectural or urban heritage project is lost.

3D visualization in virtual environment for lost or unbuilt architecture is an area of study for couple of decades (Novitski, 1998). With the advancement in digital technologies for 3D visualization in architecture, such studies provide photo realistic virtual reconstructions as well as implementations of augmented, virtual or mixed reality examples.

With this project Geographical Information Systems (GIS) has been assessed for data storage and management purposes of lost architectural heritage examples, in addition to $3 \mathrm{D}$ visualization in virtual environment.

\subsection{Izmir as Case Study}

Izmir in Turkey (Figure - 1) has been chosen as the case study for this project. Its historical prominence as one of the key trade points in Eastern Mediterranean region for centuries designates the city as a location with architectural examples from different cultures and civilizations. However, previous and on-going urban developments in its historic neighbourhoods, exemplifies Izmir as a good model to capture several lost architectural heritage buildings.

Izmir has been an important port city on the Aegean coast of Turkey and it has been a vibrant commercial district since Antiquity attracting different ethnic and religious communities. In the early 1900 s, communities in Izmir were from Turkish,
Greek, Armenian, Jewish and European backgrounds. Due to war, conflict and urban development, the majority of the city's architectural heritage was lost between 1920s and 1960s. Primarily 1922 fire destroyed approximately 25.000 buildings in the city's historic commercial and cultural city centre (Bilsel, 1997).

Availability of historic documents related to the history of the city also allows a complete understanding of the city's past. Cartographic sources such as Copelan (1834), Graves (1836), Storari (1856), Saad (1876) and Charles E. Goad (1905) (APIKAM Archives) demonstrates the urban development and changes of the city over the years since the early $19^{\text {th }}$ century. For this project, with the available detailed urban and architectural information, Charles E. Goad fire insurance plans have been utilized to trace back the city's lost architectural heritage. Additionally, several historic photographs, such as family albums, postcards, archives of government and private organizations also have been referred to in order to further study and investigate those identified architectural heritage buildings that do not exist today.

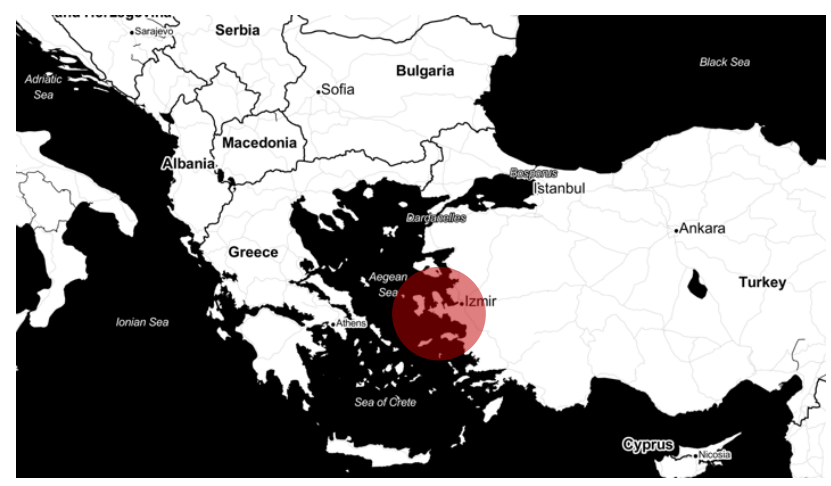

Figure 1. Location of Izmir - Turkey 


\section{CARTOGRAPHIC AND PHOTOGRAPHIC RESOURCES}

\subsection{Process}

The project with its current status includes following major stages;

- $\quad$ Literature review

- Collection of cartographic and photographic historic documents

- Utilizing photographic historic documents for image based 3D modelling

- Transfer of cartographic historic documents to digital environment

- Data visualization

As first part of the project, through a literature review various previous studies in architectural and urban scale related to history of Izmir has been reviewed. Several cartographic and photographic documents have been identified and studied in order to gather relevant information and in order to identify lost architectural heritage samples that will be studied in the following stages of the project.

After collecting the relevant historic cartographic and photographic documents, digital technologies allowed the use of these historic documents in virtual environment. This resulted with generating $2 \mathrm{D}$ and $3 \mathrm{D}$ data visualization for the lost architectural heritage examples of Izmir.

\subsection{Materials}

In order to capture Izmir's lost architectural heritage examples, 1905 fire insurance plans of Charles E. Goad (Figure - 3) were utilized in GIS environment. Since it is the most detailed and most recent cartographic resource before the great fire of Izmir in 1922, Charles E. Goad map was selected as the primary source of information. These maps presented information about late $19^{\text {th }}$ century architectural and urban characteristics of the city of Izmir. The information gathered through these maps was relevant to existing architectural heritage examples of the city of Izmir as well as the lost ones.

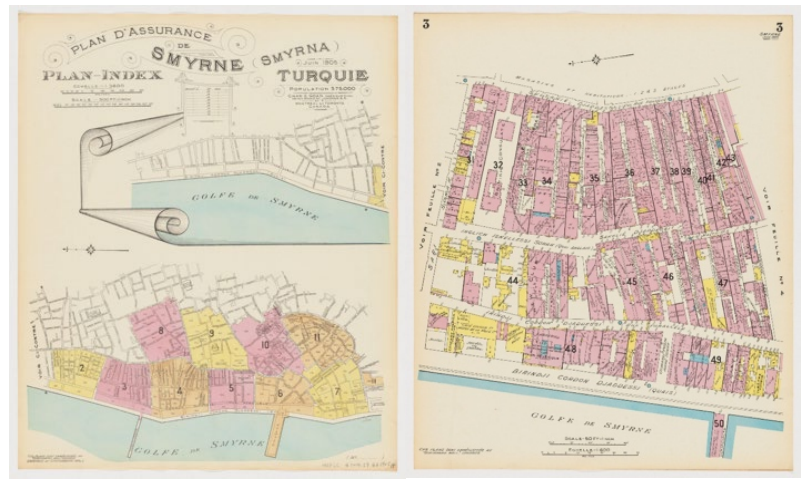

Figure 3. 1905 Charles E. Goad fire insurance plans

Charles E. Goad, a London based civil engineer, prepared fire insurance plans for Izmir in the year 1905. Fire insurance plans consisted of 11 individual maps that includes information about the buildings in 1905 in terms of their functions, structural systems, structural materials, heights, etc. In some cases, it was also possible to identify the name of the building as well as the detailed description of the commercial or industrial practice.
As the first step, individual maps of 1905 Charles E. Goad fire insurance plans were merged into one master map (Figure -4) by using photo editing software. This allowed the identification of historic neighbourhood with its architectural and urban characteristics from the year 1905 . After this point, this master map was used as the base map of GIS file and further drawings, editing and data input was done in GIS environment.

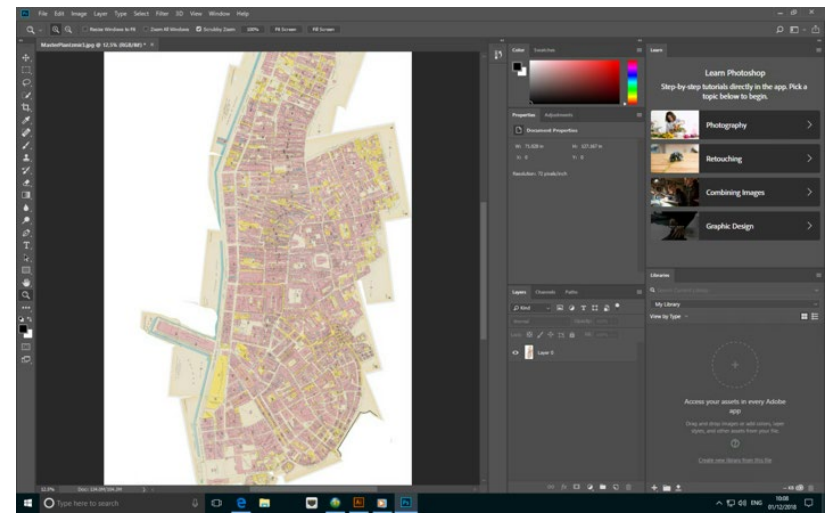

Figure 4. Master map of Charles E. Goad fire insurance plans

\subsection{D Visualization}

Another important resource for the 3D visualization of lost architectural heritage in addition to cartographic sources are photographic historic documents. In this project, historic photographs allowed to visualize the lost architectural heritage examples in digital environment.

Architectural 3D models have been created by using several historic photos by image based modelling for well known monumental buildings of the city as well as the domestic and non-monumental architectural examples.

Historic photographic documents of Beyru (2000), Yilmaz Yetkin (2003), Colonas (2005), Unlu (2006), Copsidas (1992) archives were used in order to generate these 3D architectural models. The detail of the model was relevant to the detail of the photographic evidence and accordingly various types of digital models were constructed. (Figure $5 \& 6$ )

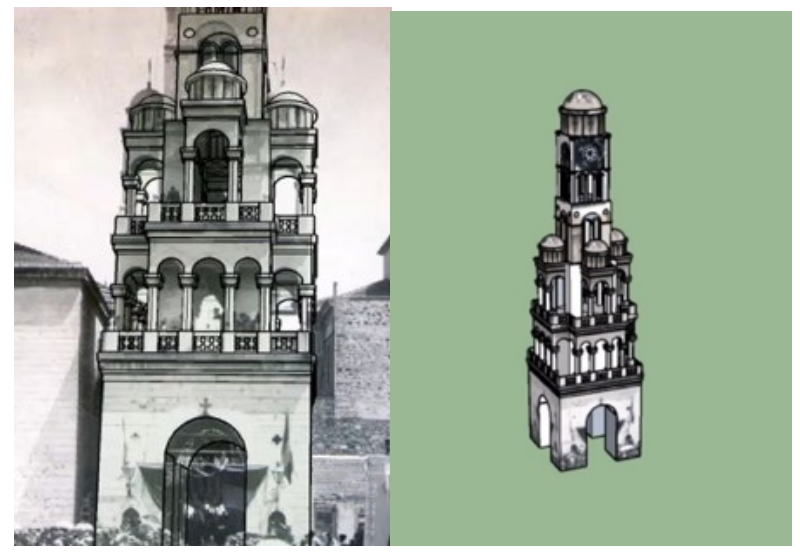

Figure 5. Virtual Reconstruction of St. Photini Church Tower 


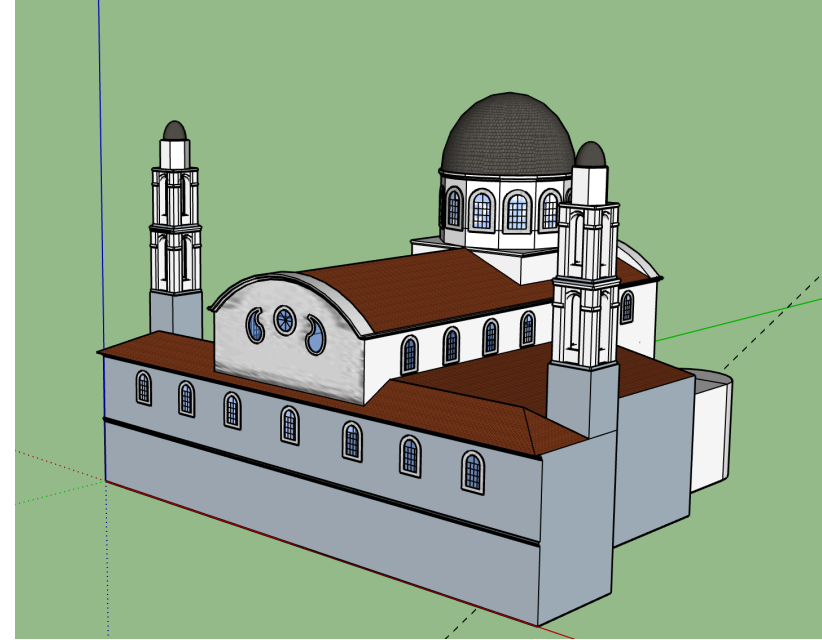

Figure 6. Virtual Reconstruction of St. George Church

Information brought from the photographic documents were mainly related to the proportions, dimensions and identification of certain finish materials of the lost architectural heritage examples of Izmir. Due to the fact that majority of these photos were black and white, the relevant information regarding the materials and finishes was also limited.

\section{VISUALIZATION THROUGH GEOGRAPHICAL} INFORMATION SYSTEMS

Utilizing the collected historic cartographic and photographic documents included the following steps in GIS environment;

- Relevant database creation

- Data input

- 2D Visualizations

- 3D Visualizations

\subsection{Database}

In line with the information brought from Charles E. Goad fire insurance plans of 1905, two study areas have been identified. First study area included detailed information about the architectural and urban characteristics of the city and second study area included information on primarily urban characteristics of the city with the exception of two architectural examples.

Accordingly, database have been created as the first step of the GIS process. Database features were points, lines and polygons according to the data type that will be generated. For the current status of the project, line and polygon features have been entered based on the information gathered. (Figure $-7 \& 8$ )

As the major data entry subject, polygon and line features included the following main attributes that has been derived from the historic documents; Name of the Building, Building Category Change Status, Main Structural System, Material of Infill, Height / Number of Storey, Finish Layer, Wash Colour, Roof Type, Roof Material, Street Names.

These attributes also has been utilized to generate 2D GIS maps and it enabled to do further cross-referencing mapping of the identified subjects.

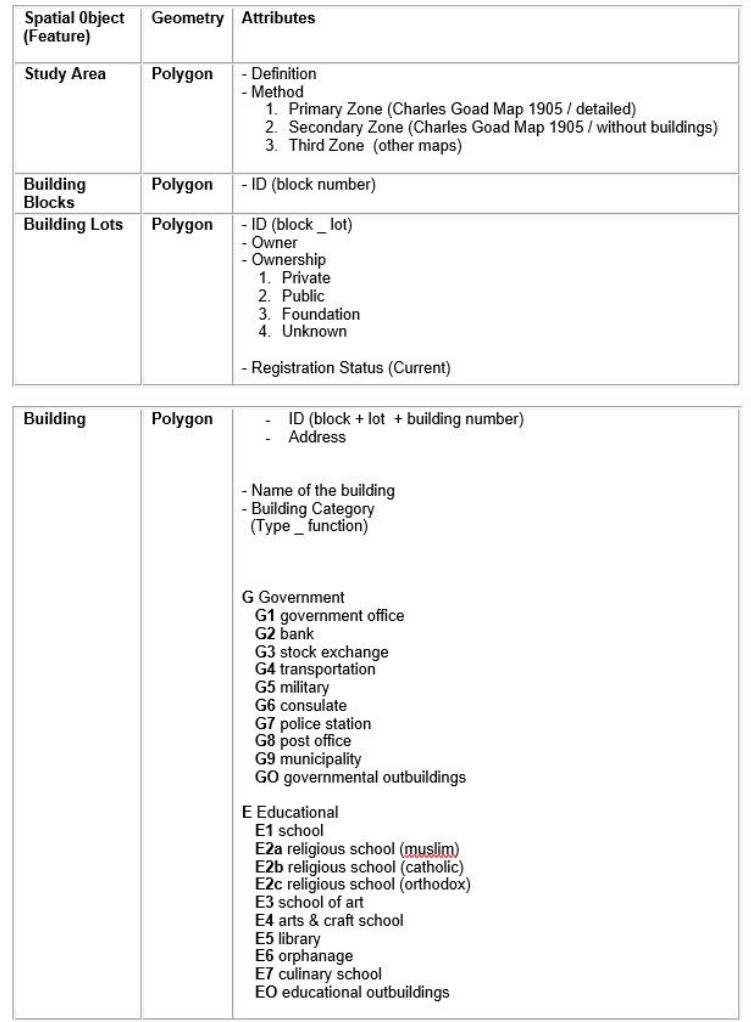

Figure 7. Database Categories

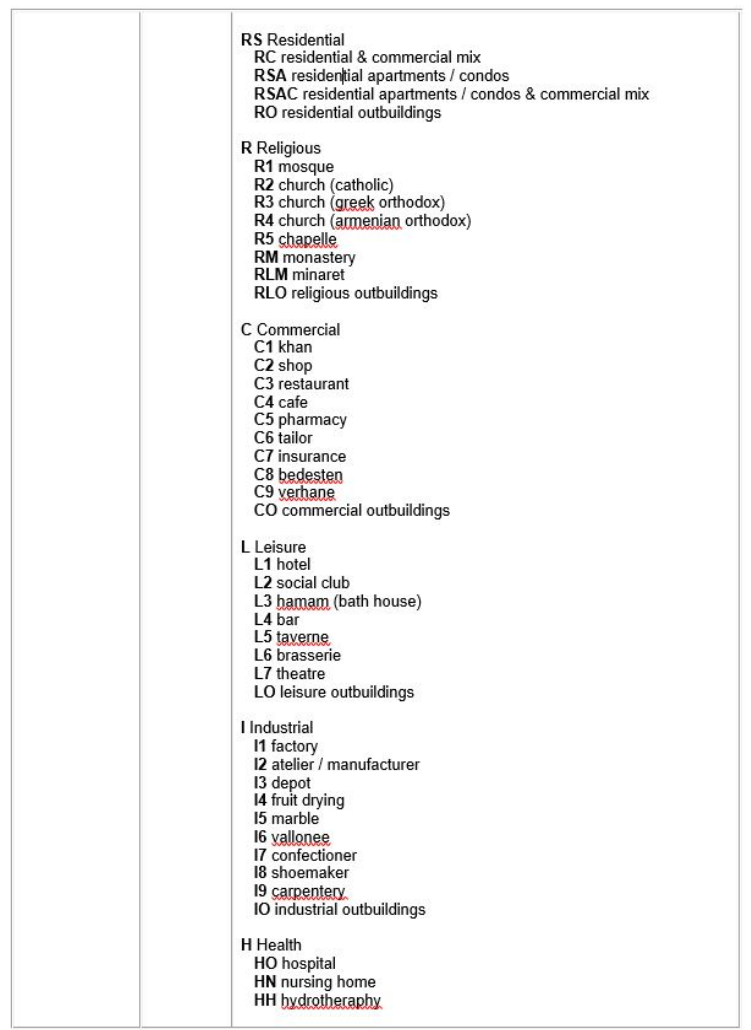

Figure 8. Database Categories 


\subsection{GIS Maps}

Finalizing the database categories, it was then possible to prepare the GIS maps for visualization of the data identified from the cartographic and photographic documents according to the database that has been created.

As the first step of the GIS data input process, combined master map superimposed on today's Izmir map by geo-referencing it to its exact position. (Figure -9) This allowed the identification of the urban and architectural changes in the historic districts of the city as well as the current locations of the identified lost architectural heritage examples.

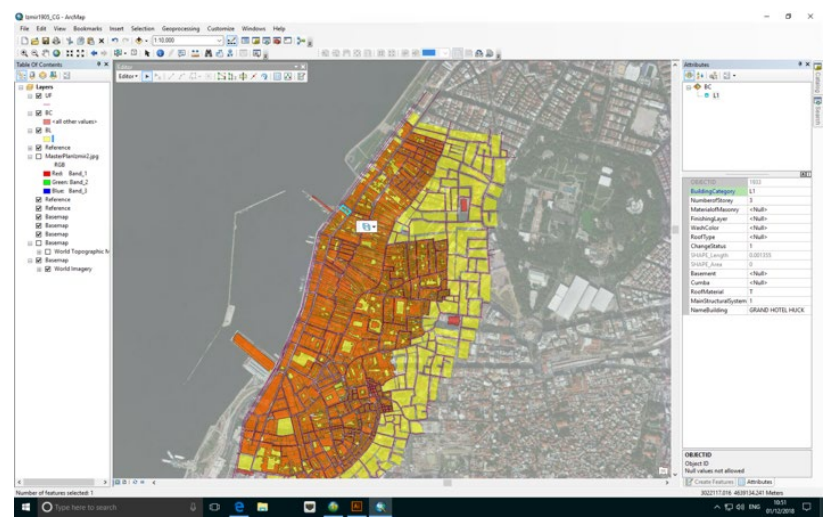

Figure 9. Data input

Drawing the 1905 map on GIS was the following step in the project. Built up areas, open areas, public open areas, streets were drawn in GIS environment. This included drawing polygons, lines and points in the map that provided basis to input data for the collected information about the area.

Several GIS maps have been created by using the database categories as the key identification of the topics of the maps. Following are some of the identified topics of the generated GIS maps; (Figure - 12, 13, 14 \& 15)

- Change Category

- Building Category

- Building Function

- Structural System

- $\quad$ Building Height

- Leisure Buildings

- Commercial and Industrial Buildings

- Finishes

GIS maps allowed the visualization of above mentioned topics in a map format, which identified different areas of the city with its primary commercial or leisure activities, as well as residential neighbourhoods.

The visualization of building characteristics 1905 Izmir was another valuable information gathered from Charles E Goad map. The topics related to the structural systems, material usage, finishes, building height and roof type and materials visualized with the help of GIS maps. It was then possible to understand and evaluate the structural material usage in the city with relation to different structural systems.

The possibility of generating maps relevant to the functions of the buildings was another topic investigated with GIS maps.
Functions related to different commercial, educational, religious and leisure activities were captured and visualized in GIS environment. The detailed commercial activities that was collected from 1905 map with relation to the production and sales facilities provided a good understanding of different economical activities that took place in the major commercial districts of Izmir.

GIS map visualizations not only helped to store, and visualize historic facts about the city with relation to building functions or building technology of 1905 Izmir, but also GIS environment gave a chance to cross-reference some of these topics and analyse various historical aspects of the city. For instance, it was possible to investigate the relationship between the buildings with certain type of structural systems and their functions or the relevance of the size of the buildings with relation to their commercial activities. It was also possible to evaluate the link between the location of certain type of activities in the city and their building height. GIS provided an environment to visualize, crossreference and evaluate the data collected from 1905 Charles E. Goad map of Izmir.

\subsection{D Visualization}

Another important outcome of the GIS maps was the 3D visualization of the city. In addition to the number of storey information gathered from Charles E. Goad map of 1905, it was also possible to identify the building heights in dimensions. This allowed the 3D visualization of the 1905 map on ArcMap. (Figure $-10 \& 11$ )

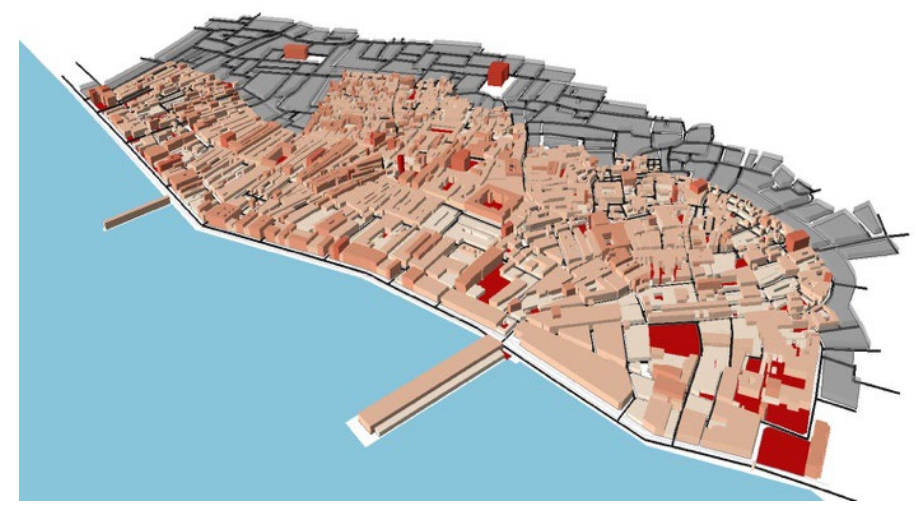

Figure 10. 3D visualization ArcScene

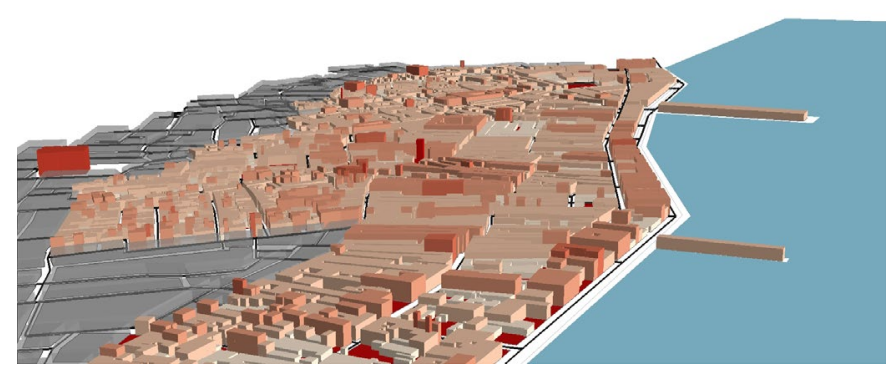

Figure 11. 3D visualization ArcScene 


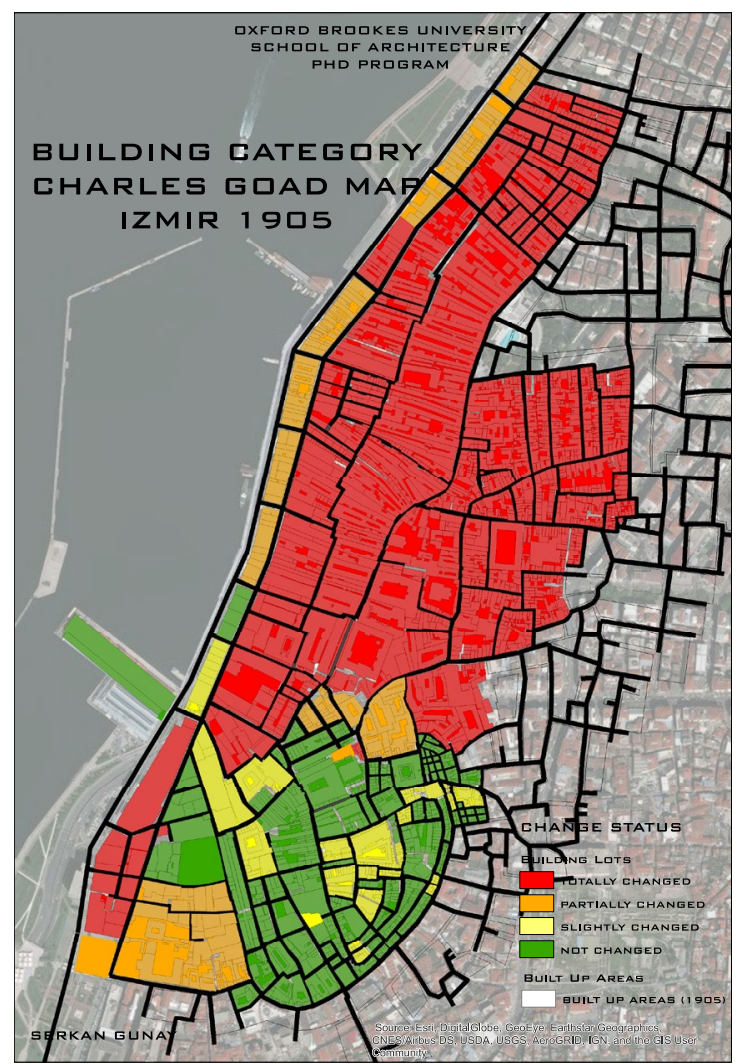

Figure 12. Change status of the buildings and building lots

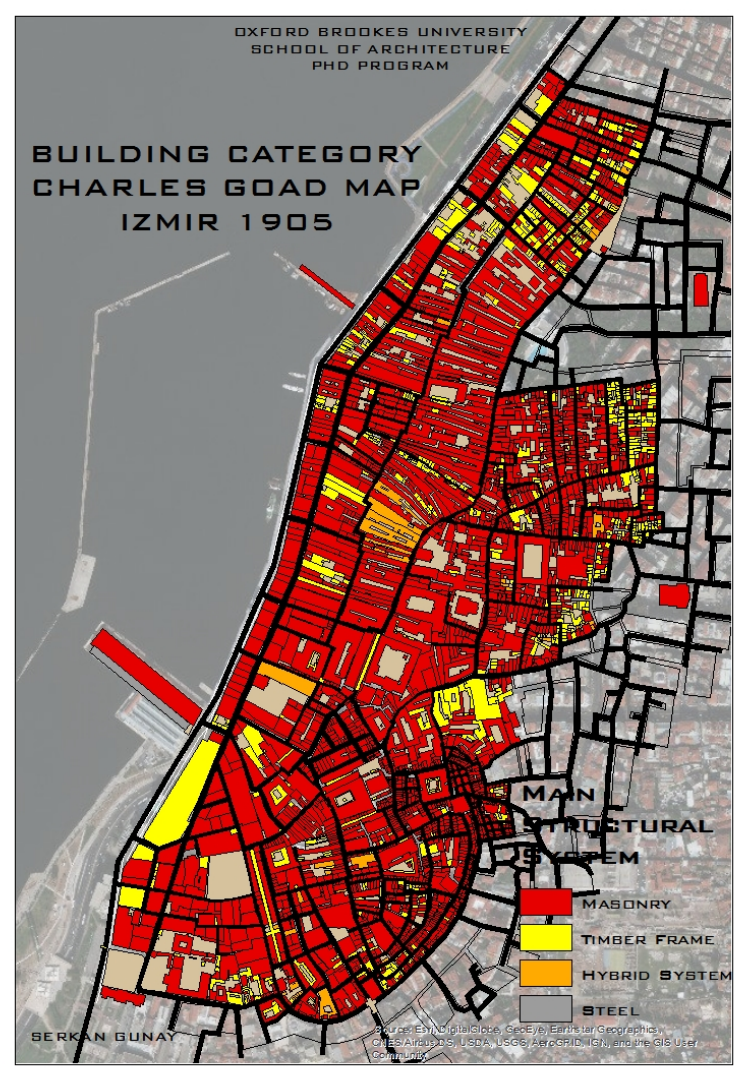

Figure 14. Structural systems

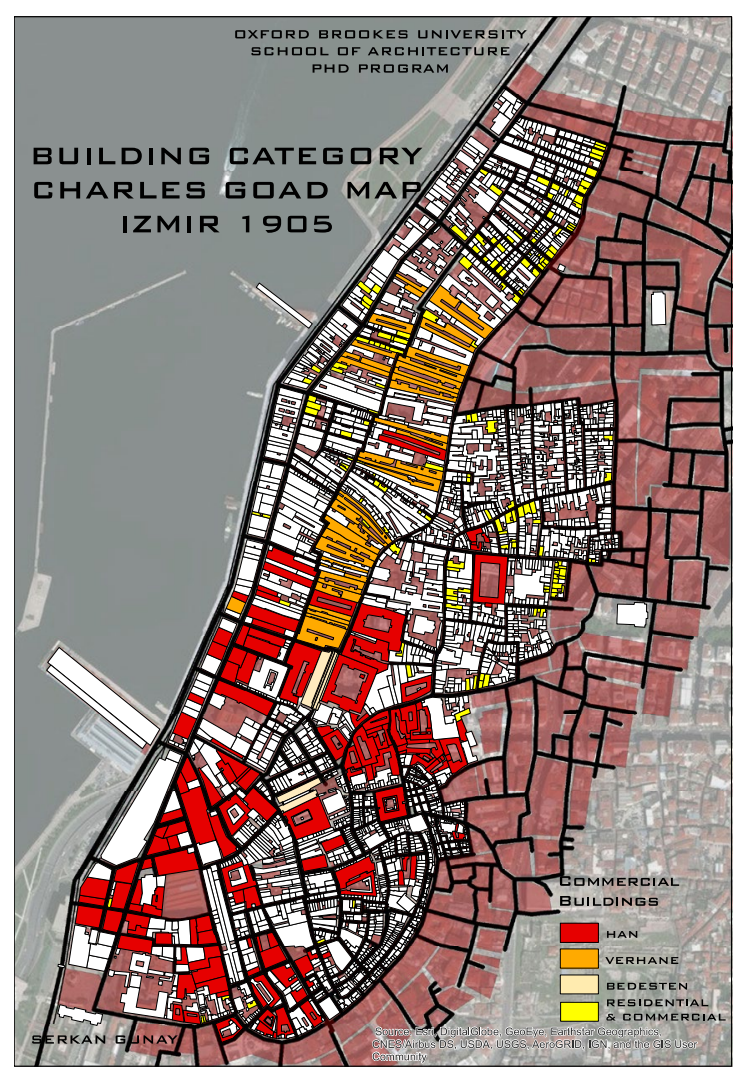

Figure 13. Commercial building categories

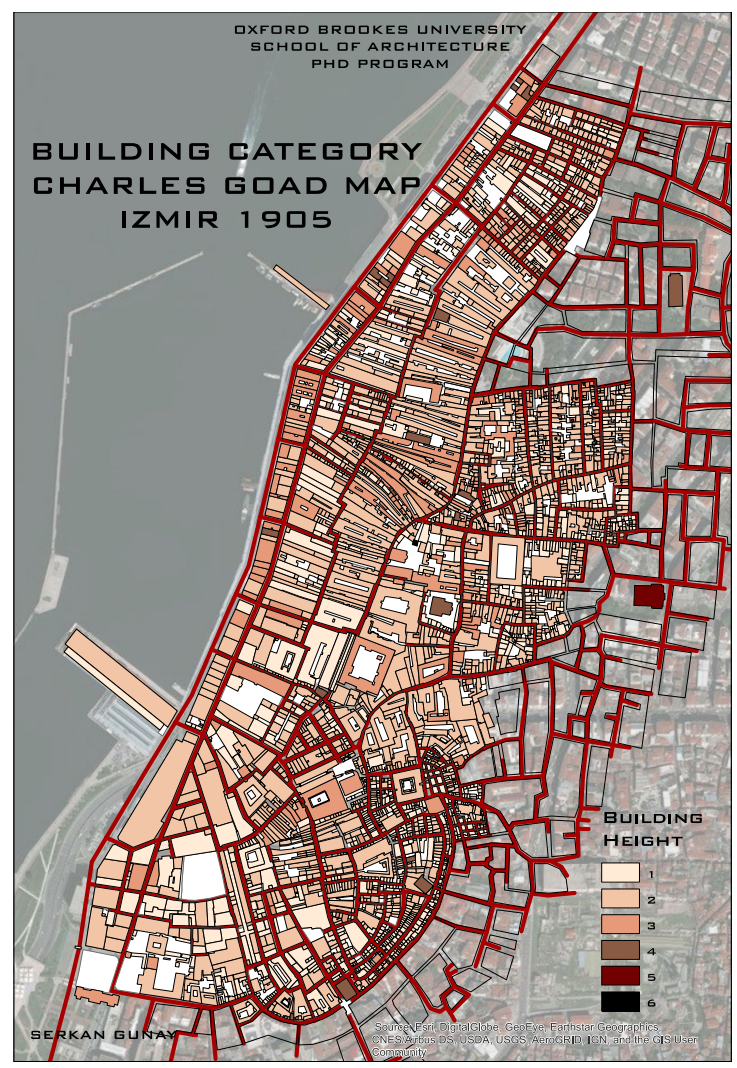

Figure 15. Building heights 


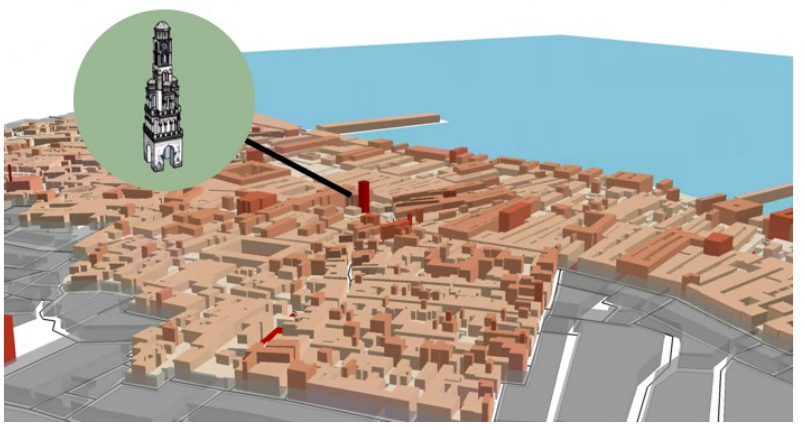

Figure 16. 3D visualization mixed media

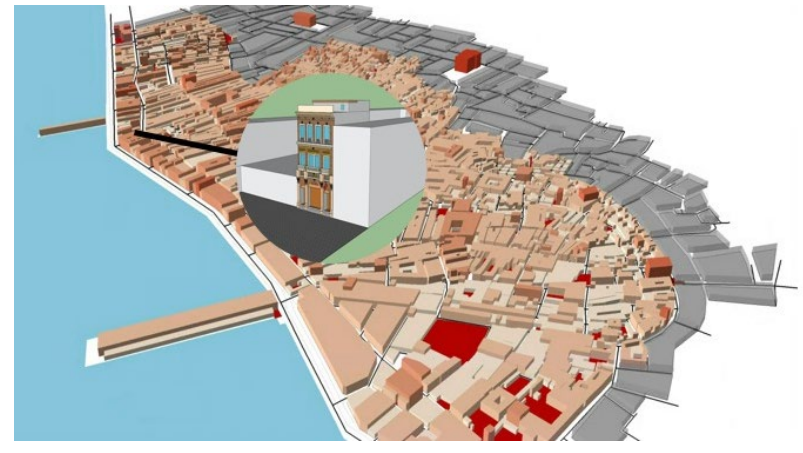

Figure 17. 3D visualization mixed media

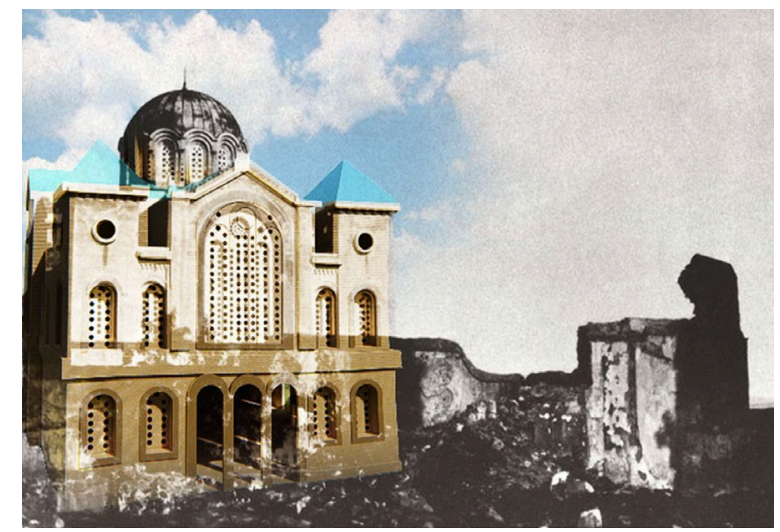

Figure 18. 3D visualization mixed media

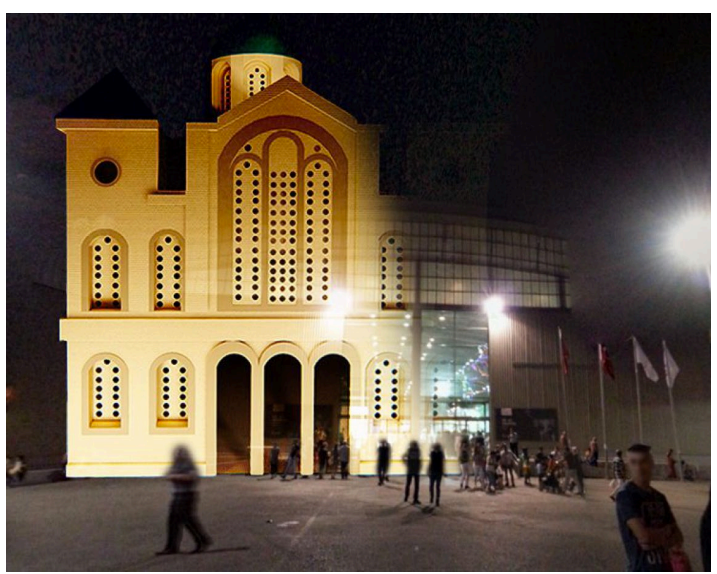

\section{CONCLUSION}

\subsection{Evaluation of 3D Visualization}

With this paper, process for the 3D visualization of lost architectural heritage by using different digital technologies has been explained. 3D visualization has been achieved by using cartographic historic documents in GIS environment and image based models were created by using historic photographic documents.

With recent technological developments it is possible to reintroduce the disappeared past of a historic settlement. This also provides a platform where people can learn more about their past and their cities' past. This is an important aspect for the historic settlements, which lost their valuable architectural and urban characteristics due to economic development, war and other reasons. At this point, using digital technologies to collect and to visualize different attributes of lost architectural heritage becomes vitally important.

GIS as a data storage and management tool, provides a valuable visualization and data management setting for lost architectural heritage research especially in urban scale. 2D and 3D data visualization capabilities of GIS by using ArcScene and ArcMap could be essential in order to gather various types of data in different formats. In addition to visualizing historic information in digital maps, it is also providing analysis and evaluation of different data by cross-references and data juxtaposition. This allows the understanding the different characteristics of lost architectural heritage within the city with the city's former urban aspects.

The challenging issue regarding the $3 \mathrm{D}$ visualization of lost architectural heritage is the reliability of the historic data. Since the buildings do not exist and in some cases the amount of information gathered from different resources is limited, it is essential to utilize verified data. The information displayed with the $3 \mathrm{D}$ reconstructed models should be verified and cross referenced from different sources.

The image based architectural models were combined with GIS $3 \mathrm{D}$ visuals by using mixed media. It was possible to hyperlink those architectural models to GIS maps and generate various visuals. This allowed the viewers to understand more about the formal and architectural characteristics of the selected lost architectural heritage samples and their geographical locations. (Figure - 16 \& 17) Additionally, detailed architectural models displayed data about the façade organization, geometric forms and ornamentations of these lost architectural heritage examples that could not be visualized in 3D in GIS environment.

The information in GIS environment regarding the geographical locations of these lost architectural heritage examples also gives chance to use different digital media in order to visualize the created architectural models. The chance to superimpose the created 3D architectural models with historic photos or with the current photos of the locations of these lost architectural heritage, gives a valuable chance to visualize different types of digital media. (Figure $-18 \& 19$ )

Figure 19. 3D visualization mixed media 


\subsection{Further Studies}

Utilizing BIM models and detailed architectural models to GIS platform will be the continuation of this research. Understanding the data visualization capabilities of different digital technologies will create enhanced virtual experiences by using different software options. This will be achieved by providing 3D visuals that displays geographical data for identified lost architectural heritage examples of the city of Izmir.

Another key point about the future parts of this research will also be the storage, management and share of the collected data. Once the digital models are created, it is possible to use the digital models in different visualization platforms in order to store and visualize as a valuable historic data. This will enhance the understanding the importance of these lost architectural heritage examples and will provide a setting to inform and educate the public about the recent past of their city with its lost values.

Additionally these generated various mixed media visualizations can be stored in GIS environment as an important and valuable data that could be shared in the future stages of this research. Further studies will look into the options of generating a web based digital platform in order to share the collected and generated visuals and information with the research professionals and the public.

\section{ACKNOWLEDGEMENTS}

The research presented with this paper is an ongoing research project with the doctoral program in Faculty of Technology, Design and Environment in the School of Architecture in Oxford Brookes University with the supervisors; Director of Studies Dr Aylin Orbasli (Reader, Oxford Brookes University) second supervisor Dr Henry Abanda (Senior Lecturer, Oxford Brookes University)

\section{REFERENCES}

Arkawi, A. 2017. Vision of the Reconstruction of Destructed Monuments of Palmyra (3D) As a Step to Rehabilitate and Preserve the Whole Site. The International Archives of the Photogrammetry, Remote Sensing and Spatial Information Sciences, Volume XLII-2/W5, 2017

Ashworth, G. J., Larkham, P. J., 1994. Building a New Heritage. London: Routledge

Beyru, R., 2000. 19. Yuzyilda Izmir'de Yasam (Life in $19^{\text {th }}$ Century Izmir). Istanbul: Literatur Yayincilik.

Copsidas, C., 1992. The Jews of Thessaloniki Through the Postcards of 1886-1917, Thessaloniki: Costis Copsidas.

Colonas, V., 2005. Greek Architects in the Ottoman Empire. Athens: Olkos Publishers

Di Mascio, D., Chuini, M., Fillwalk, J., 2016. 3D Digital Reconstruction of Lost Buildings: A First Critical Framing. Proceedings of the 34th eCAADe Conference - Volume 2, University of Oulu, Oulu, Finland, 22-26 August 2016, pp. 511520

Deggim, S., Kersten, T. P., Lindstaedt, M., Hinrichsen. N., 2017. The return of the Seigesburg - 3D Reconstruction of a Dissapeared and Forgotten Monument. The International Archives of the Photogrammetry, Remote Sensing and Spatial Information Sciences, Volume XLII-2/W3, 2017

Denker, A. 2017. Palmyra as It Once Was: 3D Virtual Reconstruction and Visualization if an Irreplaceable Lost Treasure. The International Archives of the Photogrammetry, Remote Sensing and Spatial Information Sciences, Volume XLII-2/W5, 2017

Elwood, K. L. 1998. Post-demolition Preservation: Reclaiming Lost Architecture. Unpublished Masters Thesis. Texas Tech University

Guidi, G., Russo, M. (2011) Diachronic 3D Reconstruction for Lost Cultural Heritage. International Archives of the Photogrammetry, Remote Sensing and Spatial Information Sciences, Volume XXXVIII-5/W16, 2011

Novitski, B. J. (1998). Rendering Real and Imagined Buildings. Massachusetts: Rackport Publishers

Orbasli, A., 2017. Conservation Theory in the Twenty-first Century: Slow Evolution or a Paradigm Shif. Journal of Architectural Conservation, 23:3. 157-170. doi:10.1080/13556207.2017.1368187.

Yerolympos, A., 1996. Urban Transformations in the Balkans (1820-1920). Thessaloniki: University Studio Press.

Yilmaz, F., Yetkin, S., 2003. Izmir Kartpostallari 1900 (Izmir Postcards 1900). Izmir: Izmir Municipality Publishing.

Wahbeb, W., Nebiker, S. 2017. Three Dimensional Reconstruction Workflows for Lost Cultural Heritage Monuments Exploiting Public Domain and Professional Photogrammetric Imagery. ISPRS Annals of the Photogrammetry, Remote Sensing and Spatial Information Sciences, Volume IV-2/W2, 2017 